\title{
Detecção presuntiva de aflatoxinas em amendoins comercializados na cidade do Recife, PE, Brasil
}

\author{
Presumptive detection of aflatoxins in peanuts \\ marketed in Recife, PE, Brazil
}

Recebido em: 02/09/2016

Aceito em: $13 / 02 / 2017$
Carolinne Melo Salgado Ribeiro BRAGA; Ewelynne Guedes Menezes HOLANDA; Manuela Bernardo Câmara BARBOSA; Elisangela Barbosa Silva GOMES Faculdade Pernambucana de Saúde. R. Jean Emile Favre, 422 - Imbiribeira, Recife-PE, CEP: 51200-060, Brasil.E-mail: eliscbsilva@yahoo.com.br

\begin{abstract}
Mycotoxins are natural contaminants difficult to control in food. It is estimated that about $25 \%$ of all agricultural products in the world are contaminated by these substances. Aflatoxin is the most known mycotoxin for its toxic effects in humans and animals. Based on the risks to which the population is exposed, a study for the presumptive identification of the presence of aflatoxins in industrialized peanuts seeds, purchased at supermarkets, and in samples collected in Boa Viagem beach, in Recife, state of Pernambuco was conducted. Applying the thin layer chromatography technique (TLC), the presence of aflatoxin was detected in all six analyzed samples. Aflatoxin B was found in samples of processed peanuts, and in fresh samples. Regarding the G subtype, it was observed only in one of the roasted peanuts samples. The complete elimination of aflatoxins in food is virtually impossible to occur. Therefore, the appropriate precautions should be taken, seeking to reduce the maximum aflatoxin levels in human food and animal. In addition to government oversight, food industry and the all people should also help to ensure better food safety.
\end{abstract}

Keywords: aflatoxin; Aspergillus flavus; peanuts; thin layer chromatography.

\section{RESUMO}

As micotoxinas são contaminantes naturais de difícil controle em alimentos. Estima-se que cerca de $25 \%$ de todos os produtos agrícolas do mundo estejam contaminados por tais substâncias. A aflatoxina é a micotoxina mais conhecida por seus efeitos tóxicos no homem e em animais. Com base nos riscos aos quais a população está exposta, foi realizado um estudo presuntivo para a identificação da presença de aflatoxinas em amendoins industrializados adquiridos em supermercado, e torrados coletados na Praia de Boa Viagem na cidade do Recife-PE. Aplicando a técnica de cromatografia em camada delgada (CCD), foram usadas 6 amostras onde todas apresentaram resultado positivo para a presença de aflatoxinas. Foi verificada a contaminação por aflatoxina B, tanto nas amostras de amendoim industrializado, quanto nas amostras artesanais. Em relação ao subtipo G, apenas foi observado em uma das amostras do amendoim torrado, em pequena evidência. Sabido ser praticamente impossível a eliminação total das aflatoxinas nos alimentos, há que tomar as precauções adequadas, procurando reduzir ao máximo os níveis de aflatoxina nos alimentos humanos e dos animais. Além da fiscalização do governo, a indústria alimentar e o público devem também colaborar para garantir uma melhor segurança alimentar.

Palavras-chave: aflatoxinas; Aspergillus flavus; amendoim; cromatografia em camada delgada. 


\section{INTRODUÇÃO}

Fungos são organismos ubíquos e desempenham papel importante na deterioração de alimentos (1). A partir da década de 1960, a contaminação fúngica de grãos passou a ser considerada um problema ainda mais relevante, tendo em vista a verificação de que algumas espécies eram capazes de produzir metabólitos secundários tóxicos, as micotoxinas $(1,2)$.

A história das micotoxinas surgiu em 1960, com um surto inexplicável de morte de aves (em particular perus) no Reino Unido (3). A causa do surto foi investigada e chegou-se à conclusão que o problema era a ração, produzida com amendoim, proveniente da África e Brasil $(3,4)$. O amendoim estava contaminado com uma substância tóxica fluorescente produzida pelo fungo $A s$ pergillus flavus. Assim, da expressão A. flavus toxin derivou a palavra AFLATOXINA $(3,4)$.

As aflatoxinas são metabólitos tóxicos produzidos principalmente pelo Aspergillus flavus e Aspergillus parasiticus (5), dentre os quais os mais importantes são as aflatoxinas B1, B2, G1 e G2. Elas foram assim classificadas por apresentarem fluorescência azul (Blue) e verde (Green) quando observadas sob luz ultravioleta de $365 \mathrm{~nm}$. A aflatoxina (AFB1) é o agente natural mais carcinogênico que se conhece (2), seguida das aflatoxinas G1, B2 e G2 (6). Existem duas outras substâncias denominadas M1 e M2, detectadas no leite, urina e fezes de mamíferos, que sãoresultantes do metabolismo das B1 e B2 (7).

A aflatoxina já foi identificada no milho e seus derivados (B1, B2, G1 e G2), amendoins e seus derivados (B1, B2, G1 e G2), sementes de algodão (B1, B2, G1 e G2), leite (M1) e nozes (B1, B2, G1 e G2) (8-10). Considerado um alimento altamente energético, o amendoim é consumido, por grande parte da população brasileira, em sua forma natural e em diferentes produtos (11). Nesse tipo de grão o crescimento de fungos e a produção de aflatoxinas ocorrem, em grande parte, durante o armazenamento, após a colheita (2). As aflatoxinas foram classificadas como carcinogênicas para humanos (grupo 1) pela International Agency for Research on Cancer (IARC) (11). Os principais riscos que o consumo gradativo desse alimento contaminado pode trazer à população é o câncer hepático, lesão renal e depressão do sistema imune (3). Partindo desse princípio, o mecanismo de carcinogênese se desenvolve a partir da ingestão do alimento contaminado, onde as aflatoxinas são absorvidas no trato gastrointestinal e biotransformadas primariamente no fígado, por enzimas microssomais do sistema de funções oxidases mistas 13). A forma ativada da AFB1 é o composto identificado como AFB1-epóxido. Este composto é altamente eletrofílico e capaz de reagir rapidamente por meio de ligações covalentes, com sítios nucleofílicos de macromoléculas, tais como ácido desoxirribonucléico (DNA), ácido ribonucléico (RNA) e proteínas $(13,14)$. Estas ligações determinam a formação de adutos, responsáveis pela lesão bioquímica primária produzida pelas aflatoxinas (13-15). A ligação da AFB1-epóxido com o DNA modifica a sua estrutura e, consequentemente, a sua atividade biológica, originando assim os efeitos mutagênicos e carcinogênicos da AFB1(15). Além de induzir o câncer hepático, pode ocasionar cirrose hepática e surto de hepatite viral tipo B pelo fato do fígado ser um órgão alvo para essas micotoxinas (16).

As técnicas rotineiramente usadas para determinação de micotoxinas em alimentos são principalmente Cromatografia Líquida de Alta Eficiência (CLAE), Cromatografia em Camada Delgada (CCD) e Imunoensaio Enzimático (ELISA). Todavia, qualquer que seja a técnica de escolha, deve ser reprodutível e apresentar baixo limite de deteç̧ão, uma vez que os limites máximos permitidos para tais compostos são baixos $(17,18)$. Em 2002, a legislação brasileira aprovou o regulamento técnico sobre limites máximos de aflatoxinas admissíveis no leite, no amendoim e no milho, de acordo com as normas do MERCOSUL/GMC/RES. $\mathrm{N}^{\circ} 25 / 02$. Esta resolução estabelece o limite máximo admissível de 20,0 $\mu \mathrm{g} / \mathrm{kg}$ de aflatoxinas $(\mathrm{B} 1+\mathrm{B} 2+\mathrm{G} 1+\mathrm{G} 2)$ para milho em grão, farinhas ou sêmolas de milho, amendoim em casca e descascado, cru ou tostado, pastas e manteiga de amendoim (19). Este valor serve como guia no controle da qualidade dos alimentos, mas não deixa a população isenta do risco de contaminação. Em outros alimentos para consumo humano, o limite máximo para aflatoxinas totais é $30 \mu \mathrm{g} / \mathrm{kg}$, regulamentado pela Resolução N³4/76 do Ministério da Saúde (20). Contudo, no Brasil, apesar da legislação em vigor, a ocorrência de aflatoxinas tem sido observada com frequência, e em altos níveis nos alimentos utilizados para consumo humano e animal, como, milho, amendoim e derivados (21).

Visto que as aflatoxinas são altamente tóxicas, e que os produtos alimentícios, como amendoim e derivados, constituem matéria-prima (substrato) ideal para o crescimento de fungos e consequentemente produção das micotoxinas (22), o presente trabalho teve como objetivo avaliar a ocorrência de aflatoxinas, por meio da técnica de cromatografia em camada delgada, em amos- 
tras de amendoim adquiridas na praia de Boa Viagem e em supermercados na cidade do Recife, PE, Brasil.

\section{MATERIAL E MÉTODO}

A pesquisa foi realizada com amostras de amendoim torrado adquiridos na praia de Boa Viagem (PE) e amostras de amendoim processado industrialmente, adquiridos em supermercado. As análises foram realizadas no campus da Faculdade Pernambucana de Saúde (FPS). O estudo foi executado em 6 amostras alimentícias, sendo 3 de amendoim industrializado e 3 de amendoim torrado.

As amostras alimentícias de amendoim processado industrialmente foram identificadas como AMOSTRA I1, I2 e I3. Em relação às amostras de amendoim torrado, AMOSTRA T1, T2 e T3. As amostras do amendoim processado industrialmente foram da mesma marca e lote, adquiridas em embalagens pesando em média 130 g sem apresentar indício de deterioração e armazenados na prateleira à temperatura ambiente. $\mathrm{O}$ amendoim estava exposto em local seco, como recomendado pelo fabricante. As amostras vendidas na praia de Boa Viagem por ambulantes, foram adquiridas aleatoriamente em embalagens caseiras pesando em média $80 \mathrm{~g}$, e não apresentavam sinais de contaminação e ou deterioração, apesar de estarem expostas ao sol.

As amostras foram trituradas e misturadas até se tornarem homogêneas, com precauções para evitar possíveis contaminações. Da amostra tratada foram retirados $50 \mathrm{~g}$ para realização da análise. O método analítico utilizado teve como base o método da Internation Official Methods of Analysis (23), descrito na Figura 1.
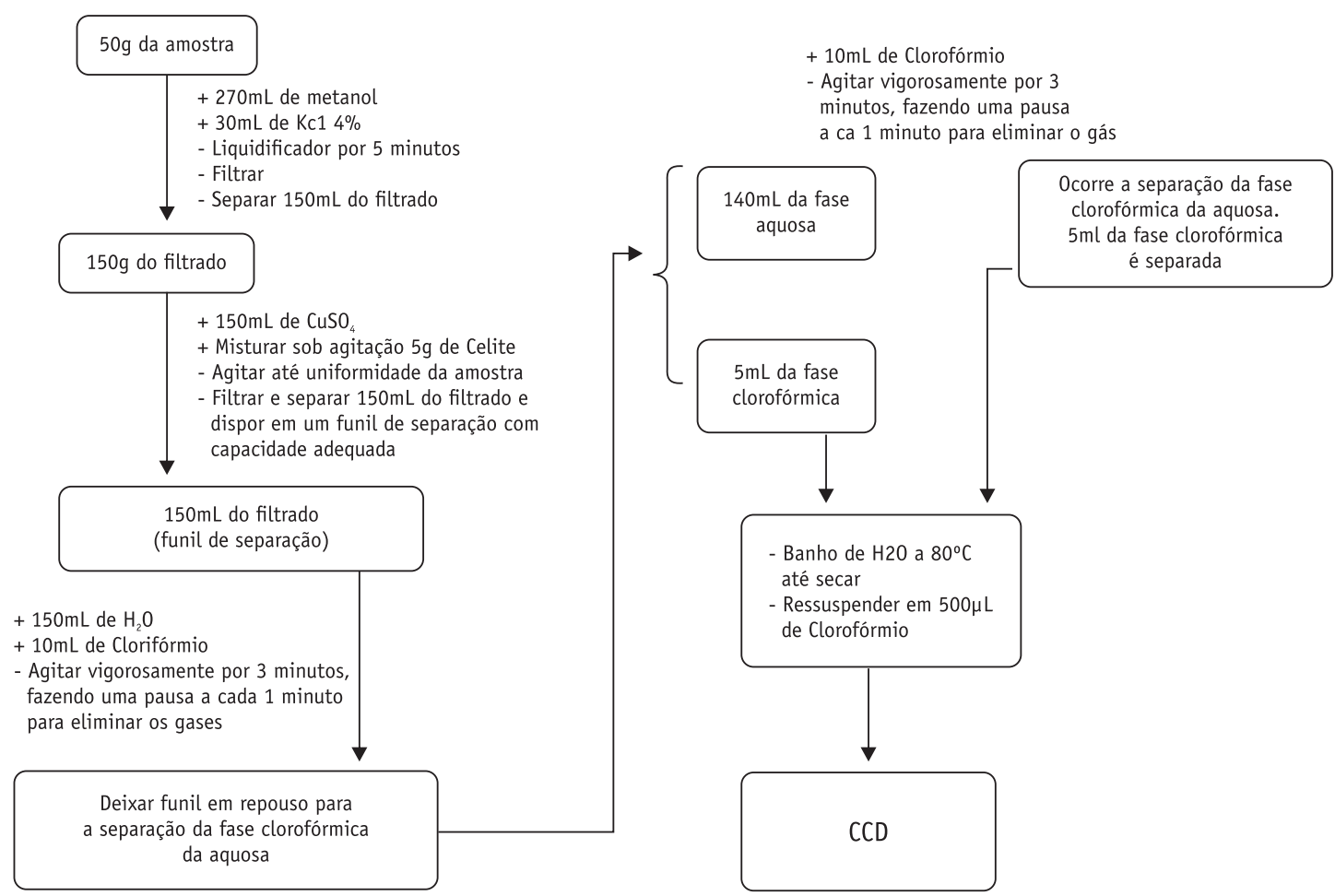

Figura 1. Fluxograma do método de separação, extração e purificação para identificação de aflatoxinas $B$ e $G$ em amostras de amendoim (adaptado de Mallman e cols., 2003).

$\mathrm{Na}$ etapa de extração, os reagentes utilizados foram metanol (Cinética $\left.{ }^{\circledR}\right)$ e cloreto de potássio (Dinâmica $\left.{ }^{\circledR}\right)$. Em seguida, foi realizada a etapa de limpeza, com a precipitação das proteínas, para a qual foram utilizados, como agentes clarificantes, sulfato de cobre pentahidratado (Dinâmica $\left.{ }^{\circledR}\right)$ e Celite (Dinâmica $\left.{ }^{\circledR}\right)$. Uma nova extração das aflatoxinas com clorofórmio $\left(\right.$ Cinética $\left.{ }^{\circledR}\right)$ foi realizada, por partição líquido-líquido, sendo a fase clorofórmica separada e posteriormente aquecida em banho-maria a $80^{\circ} \mathrm{C}$, para evaporação do solvente. Em seguida, o extrato foi ressuspendido com $500 \mu \mathrm{L}$ de clorofórmio (Cinética ${ }^{\circledR}$ ), e submetido à análise por CCD. A CCD foi realizada com eluição no sistema de solvente constituído por tolueno $\left(\operatorname{Vetec}^{\circledR}\right)$, acetato de etila $\left(\right.$ Cinética $\left.^{\circledR}\right)$ e ácido fórmico (Dinâmica ${ }^{\circledR}$ ) na proporção 60:30:10. As placas cromatográficas de sílica 
gel utilizadas foram de $60 \times 0,2 \mathrm{~mm}$ espessura (Macherey-Nagel ${ }^{\mathbb{}}$ ). A detecção presuntiva foi realizada por visualização de acordo com a intensidade da fluorescência sob luz UV a $365 \mathrm{~nm}$, para a presença das aflatoxinas e para determinação do tipo da mesma mediante a coloração.

\section{RESULTADOS E DISCUSSÃO}

Todas as amostras analisadas apresentaram contaminação por aflatoxinas e foi possível visualizar a presença de fluorescência presuntiva de aflatoxina B (azul) e de aflatoxina $\mathrm{G}$ (verde). Por meio da avaliação da intensidade da fluorescência de cada amostra (Quadro1), foi possível presumir a presença das aflatoxinas $\mathrm{B}$, tanto nas amostras de amendoim industrializado, quanto nas amostras de amendoim artesanal. Em relação ao subtipo $\mathrm{G}$ só foi observado em uma amostra de amendoim artesanal, em pequena evidência. Em relação à análise da intensidade da fluorescência (Quadro1), foi possível verificar que a intensidade da cor que representa a aflatoxina $\mathrm{B}$ foi maior para a amostra de amendoim torrado. De acordo com a Associação Brasileira da Indústria de Chocolates, Cacau, Amendoim, Balas e Derivados, a maior incidência de contaminação se dá quando o amendoim é batido, ensacado e armazenado com umidade elevada, e quando reumedece depois que já estiver $\mathrm{seco}^{24}$. Quando o alimento encontra-se em condições de umidade e temperaturas ideais, se torna menos susceptível a tal contaminação. Como citado anteriormente o amendoim torrado encontrava-se em condições inadequadas de conservação o que proporcionou um nível de contaminação maior que o amendoim industrializado, cujas condições de umidade e temperatura são monitoradas, reduzindo assim as chances de desenvolvimento fúngico.

Quadro1. Resultados obtidos por CCD em amendoim industrializado e torrado.

\begin{tabular}{|c|c|c|c|}
\hline Amostra & Cor & aflatoxina & fluorescência \\
\hline amostra I1 & azul & B & + \\
\hline amostra I2 & azul & B & + \\
\hline amostra I3 & azul & B & + \\
\hline amostra T1 & azul & B & +++ \\
\hline amostra T2 & azul & B & ++ \\
\hline amostra T3 & verde & G & + \\
\hline
\end{tabular}

I1, I2 e I3 (amostras de amendoim industrializado); T1, T2 e T3 (amostras de amendoim torrado); + (baixa intensidade de fluorescência sob luz UV $365 \mathrm{~nm}$ ); ++ (média intensidade de fluorescência sob luz UV $365 \mathrm{~nm}$ ); +++ (alta intensidade de fluorescência sob luz UV $365 \mathrm{~nm}$ ).
A alta incidência de micotoxinas encontrada nesta pesquisa é corroborada por outros achados descritos na literatura. Rocha e cols (2008) determinaram a ocorrência de aflatoxinas $B_{1}, B_{2}, G_{1}$ e $G_{2}$ em amostras de amendoim e paçoca adquiridas no comércio de Alfenas, $\mathrm{MG}$, Brasil. A técnica utilizada para a separação, identificação e quantificação das substâncias foi a CCD com prévia extração líquido-líquido dos analitos. Naquele estudo foi observado que $38 \%$ das amostras de amendoim e $13 \%$ das amostras de paçoca estavam contaminadas com aflatoxinas, sendo que as concentrações variaram de 21 a $138 \mu \mathrm{g} / \mathrm{kg}$. Todas as amostras positivas excederam o limite máximo permitido, preconizado pela legislação brasileira $(20 \mu \mathrm{g} / \mathrm{kg})$.

A partir do conhecimento dos riscos à saúde decorrente da presença de aflatoxina em alimentos, Guimarães e cols. (2013) realizaram um estudo com objetivo de avaliar a presença de aflatoxinas em amendoins assados coletados em praias da região metropolitana de Maceió, $\mathrm{AL}$, utilizando as técnicas de CCD e espectrofotometria (25). Micotoxinas foram encontradas nas sete amostras analisadas, e três amostras excederam os limites estabelecidos pelo Ministério da Saúde, que é de $30 \mu \mathrm{g} / \mathrm{kg}$ e uma amostra apresentou concentração superior a $20 \mu \mathrm{g} / \mathrm{kg}$ de aflatoxinas totais, limite máximo tolerado pelo Ministério da Agricultura, Pecuária e Abastecimento (MAPA).

Em outros achados Caldas e cols (2002) analisaram 366 amostras de alimentos consumidos no Distrito Federal, no período de julho de 1998 a dezembro de 2001, com amendoim e derivados, castanhas, milho, produtos de trigo e/ou aveia, arroz e feijão (26). As amostras foram processadas, as micotoxinas extraídas, detectadas e quantificadas por fluorescência, após separação por CCD. Foram detectadas aflatoxinas em 19,6\% das amostras, de amendoim cru e derivados, milho de pipoca, milho em grão e castanha-do-pará. Amendoim e derivados apresentaram maior incidência de contaminação por aflatoxinas $(34,7 \%)$ com amostras contendo até $1280 \mu \mathrm{g} / \mathrm{kg}$, dada como somatório de B1 e G1, e $1706 \mu \mathrm{g} / \mathrm{kg}$ de aflatoxinas totais. Das amostras positivas, B1 estava presente em 98,5\%, B2 em 93\%, G1 em 66,7\% e G2 em 65,4\%.

Os efeitos biológicos decorrentes da ação das micotoxinas estão relacionados a fatores como dosagem, duração da exposição e combinação entre as toxinas. As micotoxinas afetam o fígado e seu complexo sistema enzimático de várias formas, porém outros órgãos também são lesados (20). De acordo com as normas MERCOSUL/GMC/RES. N $N^{\circ} 25 / 02$, para o consumo humano adequado há um limite admissível de $20 \mu \mathrm{g} / \mathrm{kg}$ de aflatoxinas em alimentos $(21,22)$. Essa concentração serve 
como referência no controle da qualidade dos alimentos, porém é sabido que o consumo em longo prazo de aflatoxinas mesmo em pequenas quantidades, pode causar danos ao organismo, uma vez que estas toxinas apresentam efeitos mutagênicos e cumulativos (7). $\mathrm{O}$ amendoim é um produto consumido mundialmente. Cerca de $8 \mathrm{mi}-$ lhões de toneladas anuais de grãos destinam-se ao consumo como alimento in natura ou industrializado, e de 15 a 18 milhões são esmagados para fabricação de óleo comestível (30). Devido a esse amplo acesso, torna-se ainda mais importante a fiscalização dos limites da aflatoxina pelos órgãos federais, pois essa micotoxina tem um efeito biológico degenerativo a longo prazo. Inúmeros procedimentos analíticos vêm sendo empregados na análise e controle da presença de aflatoxinas em alimentos, por exemplo, CCD, CLAE, ELISA, biossensores e a espectroscopia no infravermelho $(22,31)$.

\section{CONCLUSÃO}

A comparação dos resultados obtidos nessa pesquisa, onde foi observada contaminação em $100 \%$ das

\section{REFERÊNCIAS}

1. Milani JM. Ecological conditions affecting mycotoxin production in cereals: a review. Vet Med (Praha). 2013; 58(8): 405-411.

2. Einloft TC, Hoeltz M, Noll IB. Aflatoxina B1 em amendoim e produtos derivados comercializados na cidade de Porto Alegre. In: Anais do X Salão de Iniciação Científica - PUCRS. 2009. Porto Alegre: ediPUCRS; 2009. p.26-28.

3. Homei A, Worboys M. Aspergillosis: A Disease of Modern Technology. In: Homei A, Worboys M. Fungal Disease in Britain and the United States 1850-2000. Basingstoke: Palgrave Macmillan. 2013. p. 118-136.

4. Freire FCO, Vieira IGP, Guedes MIF, Mendes FNP. Micotoxinas: Importância na Alimentação e na Saúde Humana e Animal. Fortaleza: Embrapa Agroindústria Tropical. 2007. 48 p.

5. Peraica M, Radić B, Lucić A, Pavlović M. Toxic effects of mycotoxins in humans. Bul. WHO. 1999; 77(9):754-766.

6. Coulombe RA. Aflatoxins. In: Sharma RP \& Salunkhe, DK. Mycotoxins and phytoalexins. Boca Raton: CRC Press. 1991, 103-43.

7. Franco BDGM. Critérios microbiológicos para avaliação da qualidade de alimentos. 1996. In: Microbiologia dos alimentos. Franco BDGM, Landgraf M. São Paulo: Atheneu, 1996. $182 \mathrm{p}$.

8. Kwiatkowski A, Alves APF. Importância da detecção e do controle de aflatoxinas em alimentos. SaBios-Rev. Saúde e Biol. 2007; 2(2): 45-54. amostras testadas, com as análises desse mesmo substrato realizadas por outros autores, mostrou que a contaminação por esse fungo permanece em um patamar elevado e representa um risco para a toda população, uma vez que produtos produzidos a partir do amendoim são largamente consumidos por humanos e animais. É preciso considerar que a ingestão do alimento contaminado, mesmo em pequenas quantidades, se feito por um longo período de tempo, pode representar danos graves ao organismo. É sabido ser praticamente impossível a eliminação total das aflatoxinas nos alimentos, portanto, há que tomar as precauções adequadas, procurando reduzir ao máximo os níveis desses compostos nos alimentos humanos e do gado. E além da fiscalização da vigilância sanitária, a indústria de alimentos e o público devem também colaborar para garantir uma melhor segurança alimentar.

\section{AGRADECIMENTOS}

À Faculdade Pernambucana de Saúde - FPS por possibilitar a execução desta pesquisa.

9. Caldas ED, Silva SC, Oliveira JN. Aflatoxinas e ocratoxina A em alimentos e riscos para a saúde humana. Rev. Saúde Pública. 2002; 36(3): 319-23.

10. Gonçalez E, Pinto MM, Manginelli S, Felici JD. Intoxicação de vacas leiteiras por farelo de algodão naturalmente contaminado com aflatoxinas. Ciênc. Rural. 2004; 34(1): 171-174.

11. Hoeltz M. Caracterização da contaminação fúngica e por micotoxinas em diferentes fases da cultura do amendoim (Arachis hypogaea L.) produzido no Rio Grande do Sul, Brasil. Tese(Doutorado em Microbiologia agrícola e do ambiente)-Universidade Federal do Rio Grande do Sul, 2009.

12. IARC. World Heath Organization. Monographs on the Evaluation of Carcinogenic Risks to Humans. 1993. (IARC. Monographs, vol. 56).

13. Pereira KL, Santos CF. Micotoxinas e seu potencial carcinogênico. Ens. cienc. 2011; 15(4): 147-165.

14. Biehl ML, Buck WB. Chemical contaminants: their metabolism and their residues. J. Food Prot. 1987; 50(12): 58-73. DOI: 10.4315/0362-028X-50.12.1058.

15. Wogan GN. Aflatoxin carcinogenesis: interspecies potency differences and relevance for human risk assessment. Prog. Clin. Biol. Res. 1992; 374: 123-137.

16. Mallmann CA., Kowalski $\mathrm{CH}$, Almeida CA, Mürmann L, Silveira VG. Prevalência de aflatoxinas em amendoim e seus derivados, destinados ao consume humano, no estado do Rio Grande do Sul. In: Anais do $2^{\circ}$ Simpósio em Ciência de Alimentos, 2003. Florianópolis, 2003. 
17. Gilbert J, Anklam E. Validation of analytical methods for determining mycotoxins in foodstuffs. Trends in Anal Chem 2002; 21:468-486. DOI: 10.1016/S01659936(02)00604-0

18. Amaral KAS, Nascimento GB, Sekiyama BL, Janeiro V, Machinski JrM. Aflatoxinas em produtos à base de milho comercializados no Brasil e riscos para a saúde humana. Ciênc Tecnol Aliment. 2006; 26(2): 336-342

19. BRASIL. Agência Nacional de Vigilância Sanitária (Anvisa). Resolução RDC no 274, de 15 de outubro de 2002. Diário Oficial da União, Brasília, 16 de outubro de 2002.

20. BRASIL. Comissão Nacional de Normas e Padrões para Alimentos (CNNPA). Resolução no 34 de 1976. Diário Oficial da União, Brasília, 19 de janeiro de 1977.

21. Sabino, M.; Zorzetto, M.A.; Pedroso, M.O.; Milanez, T.V. Incidência de aflatoxinas em amendoim e produtos derivados consumidos na cidade de São Paulo, no período de 1980 a 1987. Rev. Inst. Adolfo Lutz. 1989; 49(1): 41-44.

22. Rocha MD, Maia PP, Rodrigues MAC, Martins I. Incidência de aflatoxinas em amostras de amendoim e paçoca comercializadas na cidade de Alfenas-MG, Brasil. Rev Bras Toxicol. 2008; 21:15-19.

23. AOAC. International Official Methods of Analysis $16^{\mathrm{a}}$ ed. 1999, 2: 2-28.

24. ABICAB Associação Brasileira da Indústria de Chocolate, Cacau, Amendoim, Balas e Derivados . 2009.
25. Guimarães KCSS, Ferro FO, Rocha TJM, Silva ACP, Silva ECB. Aflatoxinas: análise por cromatografia em camada delgada e espectrofotometria de amendoins assados coletados em praias da região metropolitana de Maceió - AL. Biofar. 2013; 9:42-50.

26. Caldas ED, Silva SC, Oliveira JN. Aflatoxinas e ocratoxina A em alimentos e riscos para a saúde humana. Rev. Saúde Pública. 2002; 36:319-323.

27. Scussel, VM. Fungos em grãos armazenados. In: Lorini I, Miike LH, Scussel VM. (Ed.). Armazenagem de grãos. Campinas: Instituto Biogeneziz. 2002; 675-691.

28. MERCOSUL/GMC (Mercado Comum do Cone Sul/ Grupo Mercado Comum). Resolução no 25 de 2002. Regulamento Técnico Mercosul sobre limites máximos de aflatoxinas admissíveis no leite, amendoim e milho.

29. BRASIL. Ministério da Agricultura. RDC n ${ }^{\circ} 274$, de 15 de outubro de 2002. Diário Oficial da União, Brasília, 16 de Outubro de 2002.

30. CONAB. Companhia Nacional de Abastecimento, Ministério da Agricultura, Pecuária e Abastecimento 2004. Disponível em: <http://www.conab.gov.br/OlalaCMS/ uploads/arquivos/b57c748fe53e5e90efcfbf76a7b93421. pdf $>$. Acesso em 12 maio 2016.

31. Amaral KAS, Machinski Jr M. Métodos analíticos para a determinação de aflatoxinas em milho e seus derivados: uma revisão. Rev. Analytica 2006; 24:60-62. 